\title{
PARMÊNIDES E HERÁCLITO: DIFERENÇA E SINTONIA
}

\author{
Izabela Bocayuva* \\ izabelabocayuva@gmail.com
}

\begin{abstract}
Nós os pósteros devemos ter pensado meditadamente antes a sentença deAnaximandro, para poder refletir sobre o que Parmênides e Heráclito pensaram. Assim caduca o equívoco segundo o qual a filosofia de um foi uma doutrina do ser e a do outro uma doutrina do devir. (Heidegger - A sentença de Anaximandro)
\end{abstract}

Resumo $O$ artigo mostra como os pensamentos de Parmênides e de Heráclito estão em sintonia, na medida em que ambos denunciam o caráter ilusório da compreensão comum, constantemente cega ao que, aparentemente invisivel, justamente os conduz a investigar a respeito da natureza (perì phýseos). Habitualmente não vemos aquilo que Parmênides vê, ou seja, que a verdade é que só há o ser e que o não-ser absolutamente não há. Não percebemos que tudo o que, de algum modo, nomeamos não-ser já é, e, portanto, nesse sentido, o não-ser é somente uma ilusão. Não entendemos que a totalidade do ser sendo unicamente o que é, sendo sempre o agora - não este ou aquele agora determinado - é necessariamente imóvel porque abarca tudo. Tampouco vemos o que Heráclito indica, isto é, que a verdade é que só há uma e a mesma conjuntura sempre dinâmica do jogo dos contrários, uma guerra originária, e que a habitual percepção dos entes particulares em isolamento uns em relação aos outros é também, por sua vez, apenas ilusória. Só vemos cada coisa em sua particularidade isolada, como se cada uma pudesse ser algo acabado e fixo. Esses dois pensadores operam no plano da inteligibilidade do princípio enquanto tal, para além da compreensão

* Professora do Departamento de Filosofia da UERJ. Recebido em 20/12/2009 e aprovado em 13/02/2010.

KRITERION, Belo Horizonte, nº 122, Dez./2010, p. 399-412. 
imediata do homem comum. Ainda que variem as perspectivas desde as quais cada um nomeia a dimensão que permanece invisivel ao homem que não filosofa, ambos afirmam a unidade e 'mesmidade' no e do princípio.

Palavras-chave Phýsis, natureza, Parmênides, Heráclito

\begin{abstract}
This article shows how the thoughts of Parmenides and Heraclitus are in syntony with each other, inasmuch as both condemn the illusory character of usual understanding, always blind to that which, seemingly invisible, leads them to investigate about nature (perì phýseos). We usually we do not see what Parmenides sees, that is, that the truth is that there is only being and that, absolutely, there is not non-being. We do not realize that all we somehow name non-being already is and, thus, non-being is only an illusion. We do not understand that once the totality of being is only that which is, being always now - not this or that determined now - it is necessarily motionless because it embraces everything. Neither do we see what Heraclitus points out, that is, that the truth is that there is only one and the same, always dynamic conjuncture in the game of opposites, an originary war, and that the usual perception of individual beings, isolated in relation to each other, is, also, illusory. We only see each thing in its isolated individuality, as if each one could be some finished and fixed thing. These two thinkers operate on the intelligibility level of principles as such, beyond the immediate understanding of ordinary men. Even if the perspectives vary from which each one names that which remains invisible to the non philosopher, both assert the unity and sameness in and of the principle.
\end{abstract}

Keywords Physis, nature, Parmenides, Heraclitus

Desde a Antiguidade até nossos dias é extremamente comum vermos Heráclito e Parmênides serem tratados como pensadores que se contrapõem diametralmente um ao outro. Concordamos com Heidegger de que há um equívoco nesse tratamento que, a nosso ver, termina suas considerações onde, na verdade, deveria intensificar sua investigação. Somente uma visão muito unilateral dos fragmentos de Heráclito deixa que ele seja simplesmente enquadrado como mobilista, independentemente de qualquer discussão sobre a unidade, para não dizer: sobre um certo tipo de permanência. Da mesma forma, com relação a Parmênides, há muito mais em jogo quando ele caracteriza o 
ser em sua unidade imóvel, muito mais do que o estreito entendimento que vê nisso um mero imobilismo no sentido de uma total ausência de movimento, o que revelaria tão somente uma incongruência, um descompasso em relação à realidade.

Heráclito e Parmênides só participaram da abertura da estrada do pensamento filosófico ocidental porque ambos corresponderam - para falar como Parmênides - noéticamente ao apelo do $\operatorname{ser}^{1}$ ou então porque - para falar como Heráclito - ambos farejaram phronéticamente o invisível ${ }^{2}$. O problema fundamental é o mesmo para os dois: descrever o princípio apenas acessível ao pensamento o qual num só golpe pode ser capaz de perceber a totalidade. Justamente esse golpe instantâneo consiste no espanto admirado, próprio à "visão" do princípio - arché - nomeadamente $a$ questão, já para Anaximandro, mestre indireto deles dois por ambos terem tido contato direto com Xenóphanes de Colofón, discípulo deste pensador para quem o princípio é o ápeiron.

Procuraremos demonstrar como, desde Tales, os physiólogoi, os investigadores da phýsis, dialogam entre si a respeito do mesmo, ainda que sugerindo caminhos argumentativos diversos. Para iniciar essa demonstração procuraremos uma aproximação quanto à sentença de Anaximandro, o único fragmento legado pela tradição que nos restou desse pensador. Teremos que buscar em nós hoje uma ressonância da sentença. Vale dizer que elaboraremos apenas uma interpretação, sem pretender, com isso, esgotar a questão.

\section{A sentença de Anaximandro}

Imediatamente antes de Simplício nos legar aquela que valerá como sendo a sentença de Anaximandro, ele nos diz como esse pensador nomeia a arché, o Princípio: ápeiron, isto é, o sem limite. É a partir dessa palavra que Anaximandro dialoga com seu mestre Tales, cuja formulação de teor filosófico diz: tudo é água. É como se Anaximandro conversasse com ele assim: Ah, compreendo o que você quer dizer quando diz água: ápeiron!

Água é nenhuma determinação, nenhuma forma. Portanto, tudo, seja o que for, configura-se materialmente precisamente assim, sem ser uma forma, uma determinação acabada. Tudo consiste, pois, tão somente numa dinâmica, a dinâmica de um tornar-se: um vir a ser sempre outro, sendo sempre si mesmo. A água vem a ser sempre outra, sem jamais deixar de ser si mesma. Só por isso ela pode ser nomeada princípio de tudo, absolutamente tudo. Princípio 
uno. O salto qualitativo do primeiro pensador milesiano foi estar a argumentar acerca da origem una do ente enquanto tal, ou seja, de todo o aparecer, e de tal modo que aquilo para o que ele atenta e ao mesmo tempo aponta com o termo água não é, a rigor, este ou aquele ente, nem mesmo o conjunto de todos os entes, embora nos faça "olhar" para um elemento natural. É claro que a multiplicidade dos entes o intriga, mas justamente por provocar nele a entrevisão de uma unidade originária, uma unidade compreendida como princípio instaurador de tudo o que aparece, em seu aparecer, o que os gregos entenderam com o nome de phýsis. Há, porém, um problema. Ao mesmo tempo em que Tales evoca a água para indicar o que, enquanto princípio, não é absolutamente ente algum, ele não pode escapar de estar a "entificar", de algum modo, o que jamais pode ser um ente, pois água é inegavelmente um elemento material, visível. Anaximandro, pondo-se à altura da questão e bem compreendendo aquilo do que falava Tales, nomeia, então, o princípio de modo a evitar tal problema: ápeiron, o ilimitado, o sem determinação simplesmente.

Agora sim se alcançava uma maior clareza argumentativa para se poder dar conta do que é e de como se comporta a arché ou a phýsis. Mas o discípulo de Tales não se satisfez em só nomear o Princípio pela palavra ápeiron. Simplício, querendo explicitar o que Anaximandro queria dizer com isso, nos legou aquela argumentação que conhecemos como a sentença de Anaximandro. Nela se pode ler: (pois onde há a gênese para os entes (tà ónta), para lá surge também a destruição) segundo a necessidade; pois dão-se uns aos outros justiça (dike) e retribuição (tísin) por causa da injustiça (adikía) segundo a ordem do tempo.

A necessidade tem um papel estratégico em toda essa sentença. A partir dela, está decidido: tudo o que nasce (tà ónta) tem que morrer. Embora se fale aqui dos entes em seu fluxo de vir a ser e perecer, aquilo para o que interessa atentar não é o ente, este ou aquele ou mesmo a sua totalidade. Importa atentar para o a-peíron enquanto necessário "não-lugar".

Anaximandro, a fim de desenvolver como o "não-lugar" próprio ao princípio se realiza enquanto tal joga com termos do vocabulário jurídico da língua grega: dike, tísis e adikía. Nietzsche vê Anaximandro como um pessimista. Ele entende que nessa passagem final da sentença o pensador pré-socrático faz uma declaração acerca da vida: viver seria um castigo, um castigo por se ter nascido. Se, por um lado, concordamos que o termo adikía está diretamente associado ao fato de os entes que emergiram do indeterminado terem se determinado, por outro lado, não vemos nenhum pessimismo na afirmação de Anaximandro.

Sem dúvida, todo nascimento é a concretização de uma configuração que se instaura, uma limitação. Todo nascimento, ainda que partindo do ilimitado, 
sempre necessariamente opera uma negação deste. A instauração do ente em sua limitação "quereria", pois, esgotar a fonte de toda emergência. Assim, paradoxalmente, o ente, à medida mesmo em que é, comete injustiça. É como se a cada vez que os entes surgem, isto é, a toda hora, se forçasse o ilimitado ao que não diz respeito a ele, ao que não lhe é próprio. Quer dizer que cada/todo ente consiste, na verdade, na afirmação da negação de sua própria origem. Não há, porém, qualquer negatividade nesse jogo proporcionado pela injustiça: o nascimento do que nasce. Muito pelo contrário. Esse é o jogo da Necessidade.

Não precisamos entender, como o fazem Nietzsche e várias outras traduções que seguem mais ou menos a mesma linha, didónai díken kaì tísin (allélois) ${ }^{3}$ tes adikías, como uma expiação e julgamento. Que cada ente dê justiça um ao outro, isto é, dê um ao outro o seu lugar próprio, e retribuição ${ }^{4}$, isto é, abra passagem um para o outro porque nasceram (injustiça), isso certamente implica na phtorá, na morte pela qual deve passar tudo o que nasce. Só a partir de tal abrir passagem que implica necessariamente em pode deixar acontecer algo assim como o fluir da realidade. E por que se deveria ver nisso qualquer pessimismo? Não há aqui nem pessimismo, nem otimismo. Anaximandro nomeia com sua sentença a dinâmica necessária segundo a qual o fluxo incessante do haver pode acontecer de tal modo que o momento do nascimento de cada ente coincide com a sua morte que, por sua vez, coincide com a emergência de outro ente. Desse modo, o ilimitado segue eternamente como o "não-lugar" donde tudo emerge e para onde tudo retorna.

Anaximandro, mesmo antes da nomeação da origem de todas as coisas a partir da expressão tò eón, já estava falando do ser em sua diferença em relação ao ente. Os primeiros pensadores não eram "ainda incipientes". Era tão agudo e corajoso seu pensamento que tudo o que se formulou posteriormente sempre ficou sendo, mesmo que não se atente para isso, a tentativa de alcançar o que eles já formularam sem a menor intenção de qualquer didatismo, de qualquer espírito salvacionista.

Aquilo que pudemos brevemente perceber a partir da sentença de Anaximandro, como compreensão originária do princípio constituiu como base do pensamento tanto de Parmênides como de Heráclito. Mas se ambos tratam do mesmo, isso não significa que o façam da mesma forma. Na verdade, cada um assume uma perspectiva inteiramente diferente em relação ao outro. Devemos dizer, porém, que não são perspectivas opostas, pois não se trata de oposição,

3 Nietzsche não traduz a palavra allélois.

4 É dessa forma que traduzimos a palavra tísis. Há quem traduza por penitência, mas está perfeitamente de acordo com o uso da palavra na época de Anaximandro, traduzi-la como retribuição. 
mas de diferença de perspectiva argumentativa. A título de provocação - que é tudo o que pode pretender esse pequeno artigo -, e sugestão para uma ulterior e mais pormenorizada investigação, vamos empreender agora aqui uma consideração daquilo que entendemos consistir o teor central do que nos foi legado tanto do pensamento de Parmênides quanto do de Heráclito.

\section{Parmênides}

Se acreditarmos que Parmênides foi realmente discípulo de Xenóphanes que, por sua vez, foi discípulo de Anaximandro, também podemos acreditar que Parmênides era familiarizado com o pensamento deste último.

Parmênides também é um admirado com o que, habitualmente velado, de repente se descortina à visibilidade pensante. Essa admiração conduz a uma viagem sem volta em direção à alétheia. As moças, filhas do sol, que no Prólogo do Poema de Parmênides guiam o carro até a morada da deusa reveladora da verdade, vão tirando os véus da frente de seus rostos. Somente a partir desse movimento, o iniciado poderá logo adiante perceber a viabilidade de um único caminho. O caminho necessário. O caminho do Ser, pois só há ser. O não-ser não é, o não-ser não há. Se fosse, ele seria. Não se trata aqui de mero artifício lógico. O que Parmênides descobre, admirado, é que não há como escapar ao ser. Se por acaso dizemos "não-ser" relativamente a qualquer coisa que seja, isto só pode ser ilusão, pois o que assim é nomeado, está já mergulhado na dimensão do ser.

O Ser encerra, portanto, igualmente tudo que é, numa unidade perfeita. Daí um de seus sinais ser a imobilidade. Sempre, sem começo nem fim, sem nascer nem perecer, o Ser amarra junto tudo que é, "pois de todo lado igual a si, se estende nos limites por igual" (VIII, 49) e "é todo pleno do que é. Por isso é todo contínuo: pois ente a ente acerca" (VIII, 24 e 25). Tal amarração é sempre. A imobilidade característica do Ser, porém, nada tem a ver com estaticidade. Muito pelo contrário, nela, justamente nessa imobilidade uniabarcante é que reside a possibilidade da totalidade dos entes, incluindo todas as suas formas de movimento, embora ele precise se calar inteiramente acerca desse movimento. Pois não se trata, no Poema, de cada caso ôntico em que algo vem a ser a partir do não-ser, mas, de uma só vez, da concentração de todas as possibilidades de ser. Ao caso particular de movimento Parmênides nomeia ilusão. Toda vez que entendemos que algo se transforma dizemos que ele vem a ser o que não era, mas segundo a compreensão radical de Parmênides, cada vez que digo sobre algo que ele não é, me engano, já que nada escapa à concentração do ser que a tudo sempre já abarcou. 
Tanto quanto Anaximandro, Parmênides tenta uma aproximação do que, ainda que sumamente presente, encontra-se habitualmente velado. Ele o faz operando uma negação. Como vimos, a nomeação do Princípio por parte de Anaximandro se dá através de um termo evidentemente negativo: á -peiron, o sem limite, o sem determinação, o sem forma, o "não-lugar". Parmênides vale-se dessa mesma estratégia. Para sinalizar o Ser em sua "ausência [que é] presente firmemente em pensamento" (frag. 4 verso 1), Parmênides conta com a experiência proveniente do âmbito ôntico, pois é à medida que ela é negada que se pode chegar a indicar uma outra experiência, exclusivamente acessível ao pensamento, reservada somente àquele que pode dispor-se a se afastar da ambiência e dos limites do entendimento dos mortais comuns, e pôr-se à altura da verdade pronunciada pela deusa. No fragmento 8, encontramos os seguintes sinais do Ser: a-géneton, a-nolethrón, a-tremés, a-téleston, a-kineton, ánarchon, á-pauston, e ainda, oudé pot'en, oud'éstai, oudé ti mãllon, oudé ti cheiróteron $^{5}$. É como se Parmênides estivesse a nos dizer: o Ser não é ente e, portanto, não se comporta como os entes. Nem por isso, porém, ele é não-ser. O não-ser não é. Apenas há Ser. Eis a dimensão única, somente a partir da qual é possível dar-se o âmbito do que é, tal como fica dito entre os fragmentos 34 e 41 do fragmento 8 :
O mesmo é o que é a pensar e o pensamento de que é.
Pois sem o ente ${ }^{6}$, no qual está apalavrado, não encontrarás o pensar. Pois nenhum outro nem é nem será além do ente, pois que Partida (moira) já o prendeu para ser todo imóvel; assim será nome, tudo quanto os mortais instituíram persuadidos de ser verdadeiro, surgir e também sucumbir, ser e também não, e alterar de lugar e variar pela superfície aparente. ${ }^{7}$

Parmênides não ignora, em seu Poema, o âmbito da multiplicidade dos entes. É dele que o poeta, conduzido pelas divindades, parte. Não somente isso. Esse mesmo âmbito, como fica claramente dito no fragmento 1 deve ser inclusive levado em conta, sob pena de o poeta não dar conta de conhecer tudo. Ele também deve aprender "como as opiniões precisavam patentemente ser, atravessando tudo através de tudo" (frag. 1 verso 31 e 32). Entretanto, ainda que não a ignore e nem possa fazê-lo, não é essa perspectiva que interessa

5 ingênito, imperecível, intrépido, sem meta, imóvel, sem começo, sem fim, e ainda, nem nunca era, nem será, nem algo maior, nem algo menor. (Baseamo-nos sobretudo na tradução de Fernando Santoro)

6 O termo "ente" que aparece aqui e dois versos mais adiante não diz respeito ao mero ente entre outros, mas ao Ser, entendido por Parmênides como "O ente" enquanto tal.

7 Versos 34-41. Tradução de Fernando Santoro in: Parmênides 2. Rio de Janeiro: Azougue, 2009. 
ao pensamento filosófico. Nesse ponto, estão de acordo tanto Anaximandro quanto Parmênides. Por outro lado, Parmênides dá, em relação àquele pensador, um passo sem precedentes. Parmênides irá inaugurar em seu Poema uma discursividade que procura dar conta do Ser em sua diferença, sem apelar para o ente, ainda que use como meio de sinalizar o Ser, a negação de termos que pertencem ao plano ôntico. Em toda a primeira parte do Poema a qual está a instaurar o discurso que será doravante conhecido como discurso ontológico, Parmênides em momento algum apela para uma explicitação do que se passa com o ente, mesmo que seja para que se possa entrever, através dessa explicitação mesma, algo do que não é absolutamente da ordem dos entes. Assim tinha feito Anaximandro em sua sentença à medida que ela elucida a dinâmica a partir da qual os entes vêm a ser o que são.

Parmênides força a linguagem a servir puramente ao pensamento. Daí a viagem do Prólogo indicar um afastamento da senda dos mortais. Não é a partir do olhar e escuta, isto é, da sensibilidade habituais que será possível chegar à formulação pensante legada pela tradição como fragmento 3 , de que há mesmidade entre ser e pensar $(\text { noein })^{8}$. A sensação empírica do movimento e realidade da transformação e diferença dos entes não atinge em nada a formulação parmenídea de que o Ser é imóvel. Quando Parmênides chama tudo isso de meras ilusões, ele não quer negar o fato das experiências dos homens. Ele mesmo, enquanto homem que vive e sente, não pode negar nada disso. A questão é bem outra. Parmênides, enquanto pensador, está lidando com os limites do pensamento e da linguagem enquanto tal. Ora, é o Ser ele mesmo, o primeiro e por que não dizer único verbo, que sempre já e necessariamente se encontra nesse limite. A primeira parte do Poema de Parmênides nos força a nos transportar para esse limite em que toda a diferenciação ôntica não faz sentido algum. Na verdade, o Ser apresentado por Parmênides pode ser aproximado de algo assim como o nada, não enquanto uma negatividade, mas sim como o que absolutamente recusa qualquer determinação, tal como o ápeiron de Anaximandro.

Parmênides, assim como Anaximandro, lida com o Necessário e o nomeia Ser, o único que verdadeiramente é. Tudo o mais não sendo senão "variação" sobre esse mesmo tema intransponível. Mas falta ainda dizer que se o pensador de Eléia, a fim de conduzir a linguagem para seu limite enquanto discurso que nomeia o Ser em sua manifestação pura, inaugura uma forma discursiva que podemos chamar de lógica, isso, porém, não significa que seu pensamento 
estivesse imbuído de uma preocupação lógica no sentido do puro formalismo lógico que conhecemos e que começou a se desenvolver certamente a partir do pensamento e discursividade abertos por ele. Embora conserve uma carga lógica extraordinária e permaneça como fonte para discussões nesse âmbito da reflexão filosófica, não se pode de modo algum, negligenciar a tão forte, ou mais, carga ontológica presente no Poema de Parmênides.

\section{Heráclito}

A preocupação de Heráclito também é a phýsis, a emergência enquanto tal do que de algum modo emerge, é. Por isso mesmo, devemos entender que a força de seu pensamento não está na dedicação aos entes em sua multiplicidade. Heráclito, tanto quanto Anaximandro e Parmênides não se ocupa, enquanto pensador, com este ou aquele ente particular, nem mesmo com todo o conjunto de entes particulares, como se costuma pensar quando se afirma despreocupadamente que Heráclito ocupa-se pura e simplesmente com o fluxo das coisas, o devir.

Poderíamos dizer que Heráclito também se interessa pela explicitação do Ser, desde que façamos a ressalva de que o que aqui se está nomeando Ser, tem o caráter de princípio sem jamais se esgotar no modo de ser dos entes em suas configurações particulares e parciais. Heráclito nomeia com o termo lógos o que aqui nomeamos Ser, o único que é. Lógos: uma instância reunidora, sempre constante, que abriga o conflito, a convergência e a divergência. Mas que o lógos implique no jogo conflitante de divergência e convergência, isso, no contexto do pensamento do efésio, não quer iluminar senão a visão de unidade originária apenas acessível ao homem realmente investigador, nos mesmos moldes daquele poeta que foi, no Poema de Parmênides, conduzido através das portas do dia e da noite, até a deusa que profere a verdade a quem está à altura de ouvi-la.

É, porém, notória a diferença de perspectivas entre Heráclito e Parmênides quando cada um quer mostrar aquilo que, ainda que vigindo constantemente, costuma permanecer encoberto. No entanto, veremos que os dois não divergem no principal. Ambos percebem o Princípio como unidade, a qual permanece habitualmente encoberta.

Heráclito também chamou de kósmos o princípio. No fragmento 89, conservado a partir de escritos de Plutarco, o pensador de Éfeso diz "ser o cosmo, para os acordados, uno e comum (koinón), enquanto, dentre os que dormem, cada qual se volta para seu cosmo particular". Sobre o kósmos ele ainda diz o seguinte, no fragmento 30, comentado por Clemente de Alexandria: 
"O cosmo, o mesmo (autón) para todos, nenhum dos deuses e nenhum dos homens o fez, mas sempre foi, é e será, fogo sempre vivo, acendendo segundo medidas e segundo medidas apagando". O cosmo uno e comum, incriado, mas sempre sendo, aparece assim para os acordados, mas encobre-se para os que dormem, embora também para esses ele sempre seja, já que é comum. Aqueles "que dormem" são justamente os que não se dão conta da unidade e mesmidade do kósmos. Eles o compreendem fragmentariamente a partir dos entes tomados como entidades fixas e isoladas umas das outras. Sobre os que dormem, mas também sobre o kósmos, nomeado lógos nesse momento preciso, nos falam os dois fragmentos tidos como sendo os primeiros do livro de Heráclito. Desta vez é Sexto Empírico quem comenta:

esse lógos, sendo sempre, não são os homens capazes de inteligir (axúneton) tanto antes de ouvir como depois de o ouvirem; todas as coisas vêm a ser, segundo o lógos, e ainda assim parecem inexperientes, embora se experimentem nas palavras e ações, tais quais eu exponho, distinguindo cada coisa segundo a emergência (katà phýsin) e enunciando como se comporta. Aos outros homens, encobre-se tanto o que fazem acordados como esquecem o que fazem dormindo. (Frag. 1)

Um pouco mais adiante em seu livro ele teria ainda dito: "Embora sendo o lógos comum (xúnon), a massa (hói pollói) vive como se tivesse um entendimento particular" (Frag. 2).

Embora o tema agora seja o lógos, a afinidade destes e daqueles fragmentos é evidente, mais ainda quando ouvimos também o fragmento 72 que diz: "Do lógos com que sempre lidam se afastam, e por isso as coisas que encontram lhes parecem estranhas." Em contraste com os outros homens - os muitos (hói pollói), a massa -, somente o pensador vislumbra uma outra dimensão da realidade, a phýsis, que permanece encoberta como está dito no fragmento 123: "[a] emergência enquanto tal ama ocultar-se". A massa só vê o visível aos olhos sensíveis, só escuta o audível aos ouvidos sensíveis. Seu estranhamento vem da incompreensão da invisível articulação de tudo, vem, portanto, de seu olhar para as coisas em sua particularidade e isolamento. A grande maioria dos homens, na maioria das vezes, permanece insensível à compreensão da realidade como unidade. Não uma unidade simples, mas sim enquanto conjuntura articulada que ela é. Segundo o fragmento $50^{9}$, é sábio, ao perceber o lógos, com ele concordar "dizendo" também: hén pánta, tudo é um. Trata-se da concordância com o pronunciamento do lógos, um pronunciamento não verbal

9 Frag. 50: Se auscultares não a mim, mas ao lógos, sábio é concordar (homologein): tudo é um (hén pánta). 
e, portanto, não sensível, mas apenas inteligível. Pensamento, como o único que pode ter acesso à inteligível fala do lógos, diz respeito, para Heráclito, tão somente à compreensão da realidade a partir da unidade.

Segundo Heráclito, tal pronunciamento não verbal acerca da unidade que reúne o todo de modo articulado, revela à percepção do inteligível, própria ao pensador, uma constante guerra $\left(\right.$ pólemos $^{10}$ ) na origem, mas igualmente um constante movimento representado pelo fluxo dos rios. Se Parmênides e Heráclito vislumbram o Princípio como unidade, divergem diametralmente no modo de caracterizar essa unidade. Enquanto o primeiro sinaliza o Ser que tudo abarca como imobilidade pura, Heráclito prefere descrever o modo de tudo estar contido no Um, à medida que tal unidade não se deixa abarcar em nenhum estado, como movimento que não tem chance de fixar-se. Eis porque tradicionalmente um é chamado imobilista e o outro, mobilista. Mas, como já vimos, "o imobilismo" parmenídeo nada ter a ver com qualquer tipo de estaticidade, bem como "o mobilismo" heraclítico não é suficientemente compreendido se o "entendemos" a partir da visualização do movimento numa dimensão ôntica da realidade, embora haja imagens em alguns de seus fragmentos que podem deixar margem para um tipo de interpretação apressada nesse sentido.

Dois de seus famosos fragmentos dizem: 1) que "nos mesmos rios entramos e não entramos, somos e não somos" (Frag. 49a) e 2) "não é possível entrar duas vezes no mesmo rio" (Frag. 91). O mais importante na evidente alusão aqui feita ao movimento não é, porém, como muitos pensam, o aspecto do deslocamento no espaço, nem mesmo a transformação do ponto de vista dos entes, do ponto de vista dos que tomam esta ou aquela forma. O que realmente importa para o pensamento filosófico resguardado nos dois fragmentos citados acima é a afirmação da consistência-nenhuma que constitui fundamentalmente a originariedade da realidade, concomitantemente à noção do conflito ou guerra originária (pólemos) que consta em outros fragmentos seus. Ressoa neste momento, mais uma vez, a concepção que Anaximandro tem de arché: ápeiron.

$\mathrm{O}$ fenômeno da guerra originária constitutiva da Unidade abarcando o todo não deixa jamais que o Princípio se esgote em nenhuma configuração ôntica, as quais, tendo de existir, sempre apenas serão concretizações particu-

10 Cf. fragmentos 53: De todas as coisas a guerra é pai, de todas as coisas é senhor; a uns mostrou deuses, a outros, homens; de uns fez escravos, de outros, livres. E fragmento 80: Se é necessário a guerra (pólemon), sendo união (xúnon), e a justiça, sendo conflito (érin), é também necessidade tudo o que vem a ser segundo o conflito. 
lares em relação ao que, segundo o vocabulário heraclítico, é nomeado lógos, o que "transmutando-se, repousa" (Frag. 84). Eis que Heráclito também fala em repouso, mas certamente não do mesmo modo em que entendemos que há estabilidade no real. A essa impressão ou mesmo certeza, Heráclito chama ilusão dos que dormem. Temos habitualmente a ilusão de que o real se apresenta em paz. De que há entes e estabilidade. Poderíamos dizer, com a forma de falar de Parmênides, que esse é o caso de homens bicéfalos. É bicéfalo aquele que, dormindo, só atenta para o real fragmentariamente. É assim que hora percebemos uma coisa e hora outra, normalmente iludidos de que aquilo que a cada vez percebemos é algo fixo. Segundo a concepção de Heráclito, porém, não há, na verdade, nada fixo. É claro que, do mesmo modo que Parmênides, ele não nega a realidade desse mundo de ilusões, enquanto homem comum que ele mesmo é ${ }^{11}$. Mas, enquanto pensador, ele tem olhos para o princípio da realidade enquanto unidade, segundo ele, sempre conjuntural e conflitante.

É, portanto fundamental, para se poder alcançar em toda a sua profundidade e amplitude a compreensão heraclítica do ser enquanto devir, não se deixar seduzir pela ideia de puro fluxo à medida que se olha para os entes. $\mathrm{O}$ horizonte orientador da noção de devir em Heráclito vem da compreensão do princípio enquanto consistência-nenhuma, isto é, a compreensão de que o logos, enquanto unidade instauradora é articulação de convergência e divergência: guerra originária. Assim, tudo "está junto" (no sentido de poder ser tudo) no lógos: tudo somente "é" o que "é" em contínua ligação com o que isso mesmo não é. Para dar um exemplo tosco, não há cadeira sem chão, chão sem parede, parede sem lado de fora, não há céu sem estrelas e assim por diante..., de tal maneira que, de modo esteriotipado, cada coisa está em estreita relação com seu contrário: "o mesmo é vivo e morto, acordado e adormecido, novo e velho: pois estes, modificando-se, são aqueles e, novamente, aqueles, modificando-se, são estes" (Frag. 88) e "as coisas frias esquentam-se, o quente esfria-se, o úmido seca, o seco umidifica-se" (Frag. 126). Essa transmutação inaparente de tudo em tudo, habitualmente invisível aos olhos da massa, é o único que há.

Embora a perspectiva orientadora do discurso de Heráclito sobre o Princípio, à medida que fala em dinâmica relação, mostre-se imediatamente como sendo oposta em relação à de Parmênides, é decisivo, até mesmo para alcançarmos a mesma profundidade e amplitude quanto à compreensão par-

11 Cf fragmento 75: $\mathrm{E}$ os que dormem, também são operários (e cooperam com o que vem a ser no mundo). 
menídea do Ser, nos darmos conta da mesmidade à qual pertencem os dois pensadores.

\section{Anaximandro, Parmênides e Heráclito}

Pelo que pudemos perceber a partir da investigação ainda introdutória que aqui estivemos a empreender, Anaximandro, Parmênides e Heráclito participam da mesma tradição de pensamento. Todos eles anunciam o que permanece invisível aos olhos do homem em sua lida prática cotidiana.

Habitualmente não vemos, como Anaximandro o faz, o ilimitado como origem de tudo, como princípio do que tem um limite, nem tampouco percebemos que ter limite implica na coincidência de nascimento e morte. Só vemos costumeiramente o que de algum modo é determinado. Vemos, isso sim, que uma coisa nasce aqui e morre ali, nasce por isto e morre por aquilo.

Habitualmente não vemos, como Parmênides, que a verdade é que só há o ser e o não ser absolutamente não há. Não percebemos que tudo o que nomeamos não ser já é, e, portanto, nesse sentido, o não ser é somente ilusão e, sendo assim, o movimento, acontecimento que sempre supõe o não ser, é ilusão. Não entendemos que a totalidade é sempre o instante, não este ou aquele instante determinado, mas "o" instante e que por isso mesmo é imóvel, instantâneo. Só vemos todas as coisas em sua particularidade, podendo mudar de figura. Não temos olhos para a necessária imobilidade parmenídea do ser.

Habitualmente não vemos, como Heráclito, que a verdade é que só há a mesma conjuntura a qual vive a partir da guerra originária, e que o particular que se encontraria isolado das outras coisas em sua particularidade, é apenas ilusão. Só vemos cada coisa em sua particularidade, em sua condição aparentemente fixa. Não temos olhos para a conjuntura dinâmica ou mobilidade heraclítica.

Como já foi dito, é na esteira da inteligibilidade do princípio enquanto tal, para além da compreensão imediata do homem comum, que se movem os três pensadores os quais estivemos considerando. Para o pleno exercício do pensamento em toda a sua acuidade, normalmente se está simplesmente iludido. Se pudermos vislumbrar, já em Anaximandro, a indicação de uma dimensão que habitualmente permanece invisível, em Parmênides e Heráclito ela é explicitamente nomeada, ainda que variem a perspectiva desde a qual a iluminam. O primeiro foca a identidade do mesmo, acusando a ilusão do movimento e do não ser. O segundo foca a transmutação do mesmo, acusando, por sua vez, a ilusão da particularidade e da fixidez. Ambos, porém, afirmam a unidade e mesmidade no e do princípio. Ambos chamam a atenção para o equívoco dos que perdem isso de vista, a saber, a diferença entre ser e ente. Quer 
dizer que ambos chamam de equivocados aos que têm olhos exclusivamente para os entes, isto é, a grande maioria dos homens.

Em meio a essa grande maioria, nos encontramos também nós quando julgamos rasteiramente o pensamento de Parmênides e Heráclito como meramente contrários um ao outro. Eles não se contrariam. Participam, na verdade, da mesma conversa, aquela que procura descrever o princípio, chamado por ambos: phýsis. Mas como quem conversa amigavelmente, eles podem perfeitamente apresentar diferentes argumentos, e este é exatamente o caso deles. Quando Parmênides fala dos homens de duas cabeças no fragmento 6 de seu Poema, não fala de Heráclito, como muitos pensam, mas fala, por exemplo, destes mesmos que acham que pensam, à medida que fazem o pensamento ora pensar, ora não pensar, isto por estarem a considerar exclusivamente como o grande pensador ora Heráclito, ora Parmênides.

\section{Referências}

COSTA, A. Heráclito. Fragmentos contextualizados. Tradução, apresentação e comentários: Alexandre Costa. Rio de Janeiro: Difel, 2002.

HEGEL, G. W. F. Lecciones sobre la historia de la filosofia vol I. México: Fondo de Cultura Econômica, 1955.

HEIDEGGER, M. A Sentença de Anaximandro in: Caminhos de Floresta. Lisboa: Calouste Gulbenkian, 2002. . Heráclito. Rio de Janeiro: Relume Dumará, 1998.

KIRK \& RAVEN Os filósofos Pré-socráticos. Lisboa: Calouste Gulbenkian, 1982. LES PRÉSOCRATIQUES. Paris: Gallimard, 1988.

NIETZSCHE, F. A Filosofia na Idade trágica dos gregos. Lisboa: Edições 70, 2002. . Les philosophes préplatoniciens. Paris: L'éclat, 1994.

Os Pensadores Originários. Anaximandro Parmênides Heráclito. Trad. De Emmanuel Carneiro Leão e Sérgio Wrublewski. Petrópolis: Vozes, 1991.

PARMÊNIDES Da natureza. Trad. Fernando Santoro. Primeira edição limitada ao I Seminário OUSIA de Estudos Clássicos dedicado ao Poema de Parmênides em outubro de 2006. 